\title{
Lead Acetate Induced histopathological Changes in Kidney Tissue of Rat
}

\author{
Khatere Khosravian Dehkordi ${ }^{1}$, Rahmat Allah Fatahian Dehkordi ${ }^{2}$

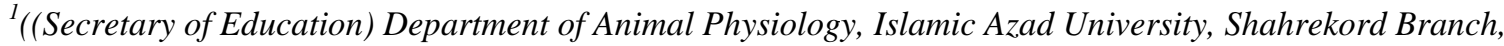 \\ Shahrekord, Iran \\ ${ }_{2}^{2}$ (Department of Basic Sciences, Faculty of Veterinary Medicine, University of Shahrekord, Shahrekord, Iran)
}

\begin{abstract}
One of the pollutants that can effect on the life of living animates is lead in different ways; it has toxic problem for human and animals and is gathered in the tissues and guide to harmful effects in their. The current study was carry out to investigate the histological effects caused by lead in the rat. The study was performed on 30 rat, they were divided into 3 groups. The first group was control group that received distilled water. The second groups were orally administered lead acetate $9 \mathrm{mg} / \mathrm{l}$ of body weight for 10 days. The third groups were orally administered solution of lead. The rats were anesthetized, the kidney were removed for histological studies. Histological changes which observed in the kidney were fatty degeneration, destruction tubules, and congestion within connective tissue, hemorrhage and infiltration of inflammatory cells. In this study, harmful toxic effects observed in kidney of rats.
\end{abstract}

Keywords: Lead, Histological changes, kidney

\section{Introduction}

For years, lead had been a toxic problem for human and animals [Hurst] and the most useful and complete model for toxicological studies is the toxicity of lead [kirkw, Riaz ,- Tian]. In spite of its detected hazards, this element used widely at industrial and commercial applications as in paints, plumbing, manufacture of lead acid batteries and etc [1,2].Gastrointestinal and respiratory systems are more exposed to lead and therefore create acute and chronic situations [3]. When foods are put into improperly glazed pottery or ceramic dishes, lead can enter foods. Lead also can leach into drinking water in water distribution systems of individual house $[4,5]$. Soft tissues and bone are place that the ingested and absorbed lead was stored and the highest lead concentration occurs within the teeth, bone, lung, liver brain, kidney and spleen [6]. The histomorphometrical properties of the renal tissue following lead intoxication are not evidenced. This study was performed to characterize the possible histomorphometric changes in the renal tissues following experimental lead poisoning in rats.

\subsection{Animals}

\section{Materials And Methods}

Twenty adult male rats (Rattusnorvegicusalbinus) that were 2 months old, weighing $205 \pm 35 \mathrm{~g}$, were used in this study. The animals were maintained in individual cages at the room with a 12-h light and 12 dark cycles and limited temperature of $21^{\circ} \mathrm{C}$, and were permitted access to water and standard laboratory pellets ad libitum. The assay protocol for this research was approved by the University Research Committee.

\subsection{Experiment Protocol}

Rats were randomly divided into two groups, A, B and C; $\mathrm{n}=10$ each group. The animals in group A served as the control group and got the distilled water. The group B received $9 \mathrm{mg} / \mathrm{l}$ by oral gavage of the lead acetate (fulda- Germany). The $\mathrm{C}$ group got lead solution for comparison. Experiment design was followed for 10 consecutive days in all groups.

\subsection{Tissue Processing}

Portions of the lobes of the liver from each rat were cut rapidly, fixed in neutral buffered formalin (10\%), were then dehydrated, with grades of ethanol $(70 \%, 80 \%, 90 \%, 95 \%$ and $100 \%)$. Cleared in xylene and embedded in paraffin wax, then 4-5 $\mu \mathrm{m}$ thick sections were obtained by rotary microtome and stained with Harris hematoxylin and Eosin.

\section{Results And Discussion}

In group A (control) normal glomeruli, each contained a tuft of glomerular capillaries surrounded by visceral and parietal layers of Bowman's capsule which are separated by narrow Bowman's space. Sections of the proximal and distal convoluted tubules were seen lined with cuboidal epithelium with strongly eosinophilic cytoplasm and vesicular central rounded nuclei (Figure 1). 
In group C similar group A normal structure in kidney was observed and all organs was seen in its ordinary statuses. in group B showed glomerular hemorrhage, atrophied glomeruli with collapsed tuft, wide Bowman's space, degenerated tubules and cellular infiltration. Studying of the histopathological effects of lead on kidney tissue of group B revealed glomerular hemorrhage, atrophied glomeruli with collapsed tufts, wide Bowman's space, degenerated tubules and cellular infiltration when compared with control group and group C. Lead element is one of the most common toxic metals and the most common route of exposure is by ingestion of lead contaminated food [7]. Once it is absorbed from gastrointestinal tract, lead bounds to erythrocytes and widely distributed initially to soft tissues such as liver, kidney, brain and spleen [1], for this reason we select the liver and kidney to describe the histological changes after lead exposure. The results of the present work showed that sub-toxic chronic lead exposure resulted in progressive tubular, glomerular and interstitial alterations. Some of these findings are in agreement with results of previous investigations [8,9]. These changes might indicate incapability of renal cells to deal with accumulated residues resulting from metabolic and structural disturbances caused by lead.

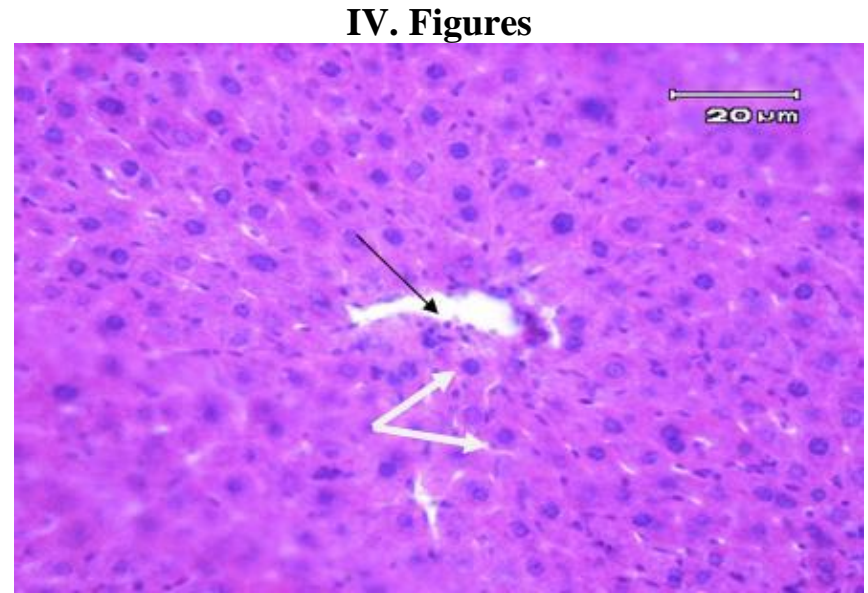

Figure 1: micrograph of liver with its details. Note the hepatocyte (white arrow) and central vein (black arrow) into liver lobe, (hematoxylin and eosin, $\times 200$ ).

\section{Conclusion}

This could be results from distribution of lead in the kidney tissue of rats where the renal blood flow enters the cortex via the blood flow. Therefore, a relative high lead concentration might reach the cortex via blood flow than that would enter the medulla [10].

This work was supported by university of shahrekord.

\section{Acknowledgements}

\section{References}

[1]. M.J. Kosnett, Heavy Metal Intoxication and Chelators. In Katzung, B. G. Basic and Clinical Pharmacology. Mc Graw-Hill, New York McGraw-Hill Medical New York, 2004

[2]. P.A. Meyer, M.J. Brown, H. Falk, Mutation research/reviews in mutation research 659 (2008) 166-175.

[3]. R.A. Goyer, T.W. Clarkson, Casarett \& Doull's Toxicology. The Basic Science of Poisons, Fifth Edition, Klaassen, CD [Ed]. McGraw-Hill Health Professions Division, ISBN 71054766 (1996) 811-867.

[4]. $\quad$ M. Loghman-Adham, Environmental Health Perspectives 105 (1997) 928.

[5]. D. Gidlow, Occupational Medicine 54 (2004) 76-81.

[6]. $\quad$ K. Plumlee, Metals and Minerals in Clinical Veterinary Toxicology, 1st Edn. Mosby, U.S.A, 2004.

[7]. R. Durgut, A. Koc, R. Gonenci, R. Bal, S. Celik, M. Guzel, Journal of Applied Biological Sciences 2 (2008) 11-18.

[8]. R. Lilis, A. Fischbein, J. Valciukas, W.E. Blumberg, I.J. Selikoff, Developments in toxicology and environmental science 8 (1979) 363-370.

[9]. C.H. Hine, H.A. Lewis, J. Northrup, S. Halls, J.W. Embree, (1981) 231-252

[10]. B.M. Jarrar, Annals of Saudi medicine 23 (2002) 10-15. 